\title{
Transportation Users' Attitudes and Choices of Ride-Hailing Services in Two Cities with Different Attributes
}

\author{
Virginia P. Sisiopiku1, Syed Ahnaf Morshed², Sahila Sarjana', Mohammed Hadi² \\ ${ }^{1}$ Department of Civil, Construction and Environmental Engineering, University of Alabama at Birmingham, Birmingham, AL, \\ USA \\ ${ }^{2}$ Department of Civil and Environmental Engineering, Florida International University, Miami, FL, USA \\ Email: vsisiopi@uab.edu
}

How to cite this paper: Sisiopiku, V.P., Morshed, S.A., Sarjana, S. and Hadi, M. (2021) Transportation Users' Attitudes and Choices of Ride-Hailing Services in Two Cities with Different Attributes. Journal of Transportation Technologies, 11, 196-212. https://doi.org/10.4236/jtts.2021.112013

Received: February 16, 2021

Accepted: April 3, 2021

Published: April 6, 2021

Copyright $\odot 2021$ by author(s) and Scientific Research Publishing Inc. This work is licensed under the Creative Commons Attribution International License (CC BY 4.0).

http://creativecommons.org/licenses/by/4.0/ (c) (i) Open Access

\begin{abstract}
The rapid technological developments in the $21^{\text {st }}$ century created new opportunities for shared-use economy applications around the globe. Among other services, Transportation Network Companies (TNCs) like Uber and Lyft emerged in the US as a transportation alternative that offered a higher level of availability, reliability, and convenience than traditional modes. However, TNCs deployment was also blamed for increases in vehicle miles traveled (VMT) in large cities that embraced TNC services early on. Concerns about TNC adoption are also magnified by the current controversy in policy and legislation as to the regulation of TNCs. These new realizations create a need to examine the transportation users' attitudes and perceptions regarding ridehailing service, after nearly a decade of service in the Unites States market. In doing so, this paper compares and contrasts results from two recently completed studies aiming at creating links between socio-demographic factors and TNC use. The paper describes the methods employed to collect the data and presents findings from the analysis of 790 users' responses in the Birmingham, AL and Miami Beach, FL markets. The study documents preferences and attitudes toward TNCs and highlights similarities and differences in travel behaviors related to local considerations. Moreover, the study uses the Least Absolute Shrinkage and Selection Operator (Lasso) method to identify predictors for TNC use based on the users' responses in Birmingham and Miami Beach case studies. Vehicle availability and waiting time emerged as the only significant predictors for the Birmingham region whereas vehicle ownership, vehicle use, residency, and prior use of transit and TNC where some of the predictors identified for the Miami Beach area. Understanding the characteristics of TNC users and the leading reasons that drive people towards the use of TNCs services is expected to help transportation agencies
\end{abstract}


and TNC providers in their efforts to plan for transportation services that meet customer needs in the future.

\section{Keywords}

Transportation Network Companies (TNC), Ride-Hailing, Travel Behavior, Mode Choice, Survey, Birmingham, Miami Beach

\section{Introduction}

Transportation Network Companies (TNCs) such as Uber and Lyft are smartphone app-based ride-hailing services that have grown rapidly over the past decade. Such services match passengers with drivers using online enabled platforms. The launch of TNC services took place in 2009, when Uber (formerly known as UberCab) introduced the service in the San Francisco area [1]. Soon after, TNCs made their appearance in various other markets across the US, thus adding transportation options that competed or complemented available transportation services. The promise to save time, increase affordability and convenience, reduce stress, and the lack of need to own and use a personal automobile has been appealing to many customers who embraced TNC services, especially in large metropolitan areas. Among available TNCs in the US market, Uber is the market leader with $65 \%$ market share.

In addition to providing user benefits, TNCs were initially perceived as a solution for urban congestion. However, in several cities in the United States (US) where these companies operate, TNCs failed to deliver on this promise. In fact, recent studies from heavily congested cities in the US have reported that TNCs took over part of the transit ridership rather than promoting ridesharing among solo drivers. To make things worse, Uber- or Lyft vehicles waiting for rides contributed to increased Vehicle Miles Traveled (VMT) and urban pollution. In addition, TNCs have been involved in regulatory and policy challenges, mainly because of the controversial aggressive models of market entry and the pushback from regulated for-hire transport industry [2].

A number of recent studies explored the emerging trend of TNC services as a mode of transportation. A concise summary is available by Sisiopiku et al. in [3]. Shaheen (2018) discussed the recent cultural shift from the auto-dependency to shared mobility and the impact of such shift on the growth of ride-hailing services such as Uber and Lyft [4]. Several studies attempted to define TNC market characteristics using surveys. These studies showed great variations in their findings depending on the geographical locations and the surveyed user demographics. For instance, studies conducted in large metropolitan areas like Boston, Chicago, Los Angeles, New York, San Francisco, Seattle and Washington D.C. showed that the typical TNC user is $18-29$ years of age and possesses an advanced degree [5]. However, TNC users in cities like Pittsburgh and Puget where predominantly 34 - 44 years old and holding Bachelors' degrees [6] [7]. 
Cirella et al. (2017) examined the differences in travel mode choice between Millennials and Generation Xers in California using inputs from 2155 individuals. When compared to Gen Xers, Millennials were three times more likely to use Uber or Lyft [8]. With respect to older transportation users, Freund et al. (2020) suggested that door-to-door assistance service could increase the use of TNC service among 65+ years old population [9]. A survey of 380 TNC users in San Francisco conducted by Rayle et al. (2014) reported that $67 \%$ of responders used ridesourcing for social/leisure trips (bars, restaurants, concerts, friends/family visits) while only $16 \%$ used it for commuting purposes. Responders reported that their leaning towards TNCs was driven by the availability of a secure payment system with short wait time and $40 \%$ of TNC users in the San Francisco region reported using their private vehicle less due to the availability of on-demand mobility sharing services [10]. A national Pew Research Center survey of 4787 American adults in 2015 found only 15\% of Americans had used ride-hailing apps, whereas one third had yet to even hear of them [11]. While the author did not find race or gender as influential factors in the use of these apps; age, education, income level and type of locale (i.e. urban, suburban, or rural) were all found to be strongly explanatory.

Overall, the literature review confirms that knowledge and utility of TNC services among travelers vary greatly in accordance to a vast array of socio-demographic variables, as with most new technology [11]. Moreover, systematic documentation of actual impacts of TNCs presence on the preferences and daily travel patterns of the transportation system users is still limited. This is due to the lack of availability of detailed data resulting from privacy concerns and resistance of TNC companies to share company data [12]. Thus, localized studies are of great value in order to document transportation users' attitudes and preferences and identify socio-demographic variables that influence the use of TNC services.

In light of this need, the objective of this study was to examine the impact of transportation users' choice preferences on the selection of ride-hailing services as a mobility option in the Southeast US. Using questionnaire responses from two different geo-locations in the Southeast (i.e., Birmingham, Alabama and Miami Beach, Florida) the study documented and compared preferences and attitudes toward TNC use as a travel mode of choice. The study considered demographic data in the analysis and interpretation of the survey findings and the identification of indicators that affect the use of TNCs at the study locations.

\section{Methodology and Data Collection}

This study compared results from two surveys that collected and documented public perceptions related to ride-hailing services in two TNC markets; namely Birmingham, AL and Miami Beach, FL. The study builds on the authors' earlier work [12] that used a questionnaire survey to understand the leading reasons and conditions that drive people towards the use of TNCs services in the Birmingham Metro Area.

Both surveys were developed using the Qualtrics Research Core tool in accor- 
dance with the Institute of Transportation Engineers Manual on Transportation Engineering (ITE) Studies guidelines [13]. Qualtrics LLC facilitated the identification and recruitment of survey participants and automated the data entry and management process. The research team obtained the survey responses from Qualtrics LLC and performed validation checks, data processing, and data analysis. All necessary approvals were obtained from the Institutional Review Board (IRB) for Human Use prior to conducting the surveys. For quality assurance, both questionnaires were pretested and refined prior to distribution.

The surveys sought to get information about users' attitudes towards using TNCs along with detailed socio-demographic such as age, gender, education level, and employment type. The demographic data were categorized based on the US Census criteria. The survey also requested participants to report detailed trip information for a typical day (i.e., 24-hr travel diary) during a typical weekday including origin and destination of each trip, travel time, trip purpose and the travel mode used. Additionally, information related to vehicle ownership, alternate mode choices, and recommendations for future transportation improvements (including expansion of the TNC services) was solicited.

Participants were presented with simple multiple-choice questions with specified context and were asked to answer each question categorically based on the context. While some survey questions were identical or similar between the two study sites, others solicited inputs on issues of unique importance to each study site. For example, since Miami Beach Area is a popular tourist spot that is busy during the weekends, Miami Beach survey participants were asked to provide trip information for a typical weekend, in addition to a typical weekday. In addition, being an adult who is residing within the geographical area of interest was a requirement for participation in the Birmingham study, but not in the Miami Beach survey in order to allow for documentation of responses from tourists that visited the Miami Beach area for recreational purposes.

The collected responses were carefully checked and validated. After eliminating any surveys that included incomplete, duplicate, or irregular answers, 451 responses from the Birmingham area and 339 from the Miami Beach area were analyzed for a total of 790 surveys. It is important to note that out of the 339 respondents in Miami Beach Area, 71 (21\%) were Miami Beach residents and the rest (79\%) were visitors from the greater Miami area or out-of-city tourists. This allowed for examination of potential differences in the preferences and attitudes toward TNCs between residents and tourists in the Miami Beach case study. For a quick reference, Table 1 summarizes characteristics of both study locations along with information relevant to the two surveys.

\section{Data Analysis and Results}

\subsection{Descriptive Analysis}

Population segmentation through demographic characteristics illustrates the size of potential TNC market in the selected study regions. Among the 451 responders from Birmingham and 339 from Miami Beach considered in the analysis, 342 
and 204 respectively were women. Based on the responses provided in the Birmingham and Miami Beach surveys, more female than male travelers are TNC users where the female to male ratio is 74:26 and 55:44 respectively.

When considering the age of the survey participants, the largest percentage of participants in both the Miami Beach and Birmingham surveys represented the young adult age group. Inspection of the survey results confirmed that the peak age group for the overall survey correlated with the TNC users. Figure 1 displays the distribution of the TNC users by age group.

Figure 2 shows the usage of modes other than private automobile in the past year for the survey participants. It can be observed that ride-hailing services were more popular (73\% FL and $45 \% \mathrm{AL})$ than public transit service and organized ride sharing programs among the users in both the regions.

Table 1. Summary characteristics of study sites and survey responses.

\begin{tabular}{|c|c|c|}
\hline & Birmingham, $\mathrm{AL}$ & Miami, FL \\
\hline Population & $1,141,309$ capita (2016 Census) & 88,885 capita (2019 Census) \\
\hline Available Travel Modes & $\begin{array}{l}\text { Private vehicle, bus, taxi, TNCs, } \\
\text { bikes, carpool, vanpool }\end{array}$ & $\begin{array}{l}\text { Private vehicle, bus, taxi, TNCs, } \\
\text { bikes, carpool, vanpool, subway }\end{array}$ \\
\hline Total Responses & 451 & 339 \\
\hline Number of Self-reported trips & 1130 & 878 \\
\hline Type of Respondents & $100 \%$ residents & $21 \%$ residents, $79 \%$ tourists \\
\hline
\end{tabular}

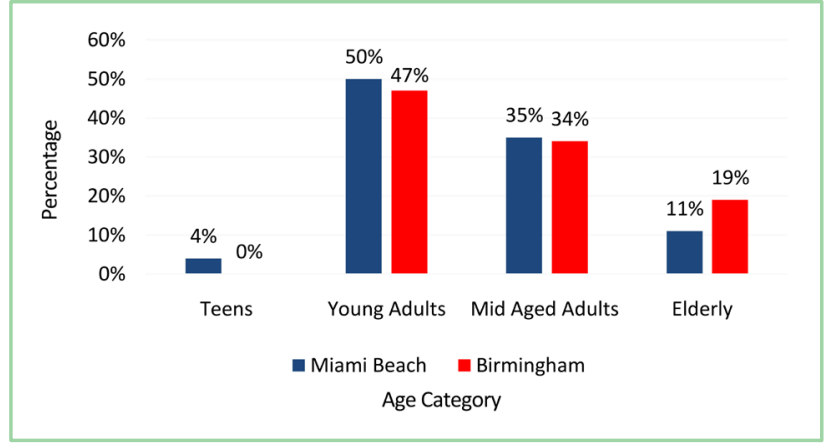

Figure 1. Age group of survey participants (TNC users).

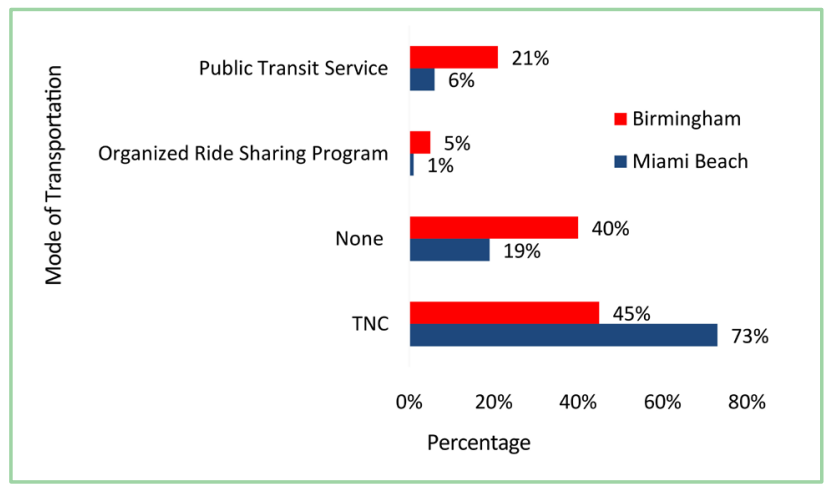

Figure 2. Modes other than private car used in the past year by the survey participants. 
As shown in Figure 3, the analysis of self-reported trip data over a 24 -hr period showed that approximately $6.4 \%$ of the reported trips in the Birmingham region were conducted by TNCs whereas in Miami Beach the reported TNC market share was higher ( $20 \%$ of the weekday trips and $17 \%$ of the weekend trips). There are many possible explanations for the difference. First, Uber was introduced in the Miami market in June 2014; more than a year and a half before coming into the Birmingham market thus users are more familiar with TNC presence. More importantly, there is the severe shortage of parking availability in the Miami Beach area, which makes ride-hailing services an attractive alternative to automobile use, especially for tourists and visitors within the Miami area. The Miami Beach area has a large number of restaurants, bars, and late night entertainment venues, which can also contribute the use, as users try to avoid driving after alcohol consumption. It is also worth noting that personal automobile usage in Birmingham is significantly higher (85\%) than that at the Miami Beach (56\%). This is consistent with earlier studies in the Birmingham area [14] [15] which reported automobile use in the Birmingham metro between $83 \%$ and $86 \%$. It is also evident that use of transit services for both regions is very low (2\%).

Additional analysis was performed to compare mode choices between weekday and weekend trips in the Miami Beach region (Figure 4). As previously mentioned, weekends are typically busy in this region due to high attraction of tourists and visitors. It can be observed that there are no major differences in the preference of mode selection in Miami Beach region based on the day of the week consideration (weekday versus weekend).

Figure 5 illustrates trip purposes of trips performed by survey respondents using TNC as their mode of transportation during typical weekdays in the Birmingham and Miami Beach regions. Additionally, the weekend trip purpose versus TNC trip data was added to assess any difference in behaviors during the weekend scenario in the Miami Beach region.

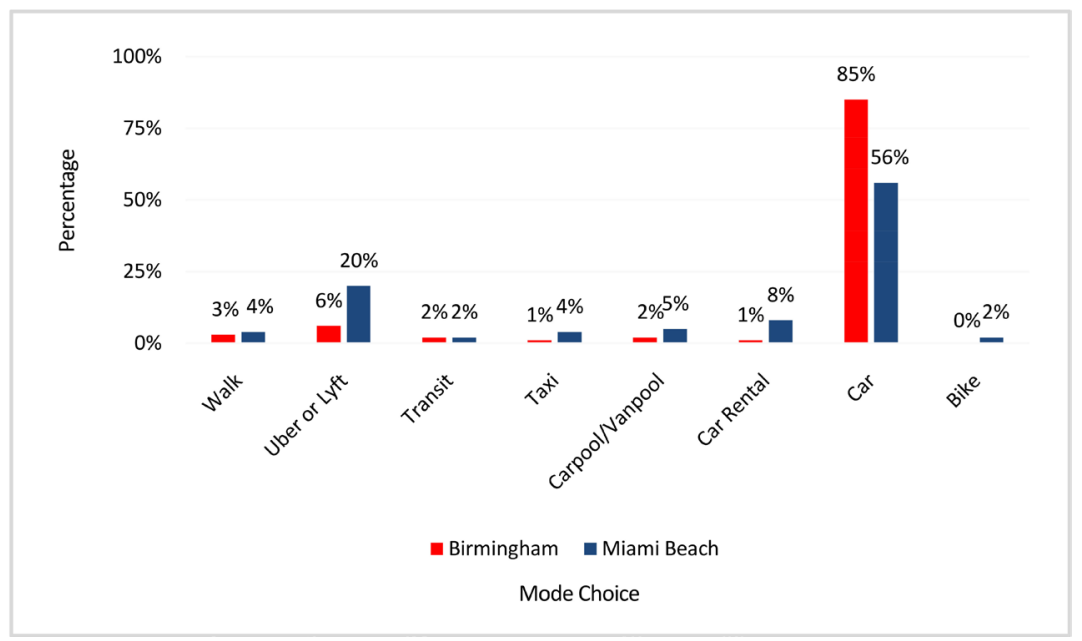

Figure 3. Mode Choices of Birmingham and Miami survey respondents. 


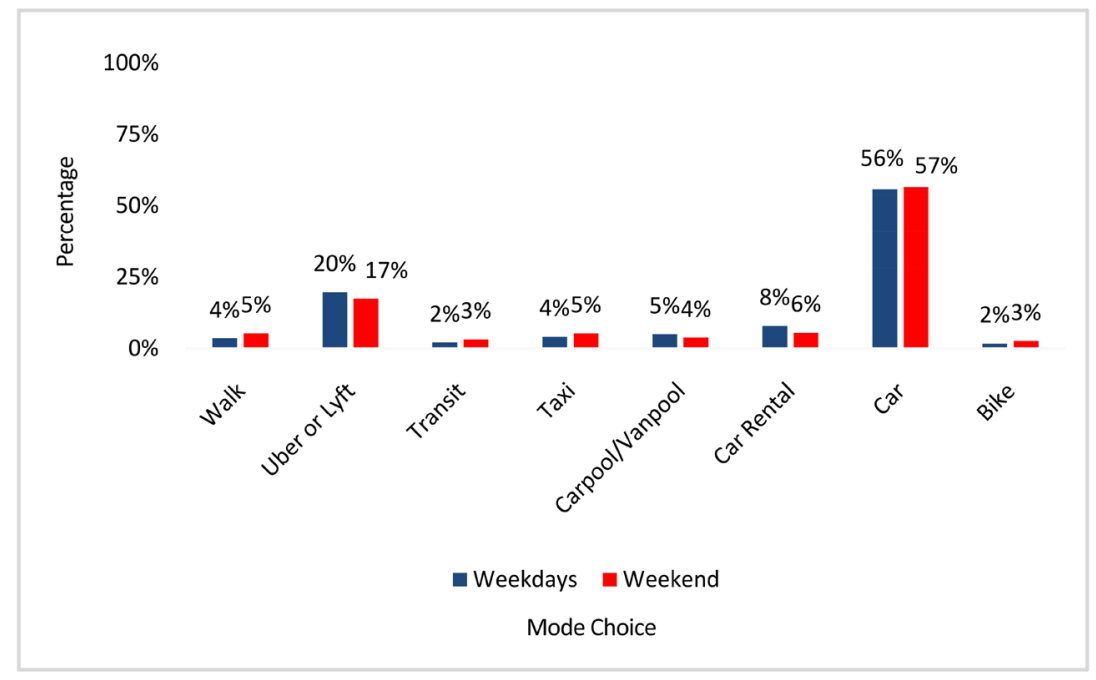

Figure 4. Mode choices of Miami Beach survey respondents during a typical weekday and a weekend.

Birmingham (Weekday)

- Miami Beach (Weekday)

Miami Beach (Weekend)

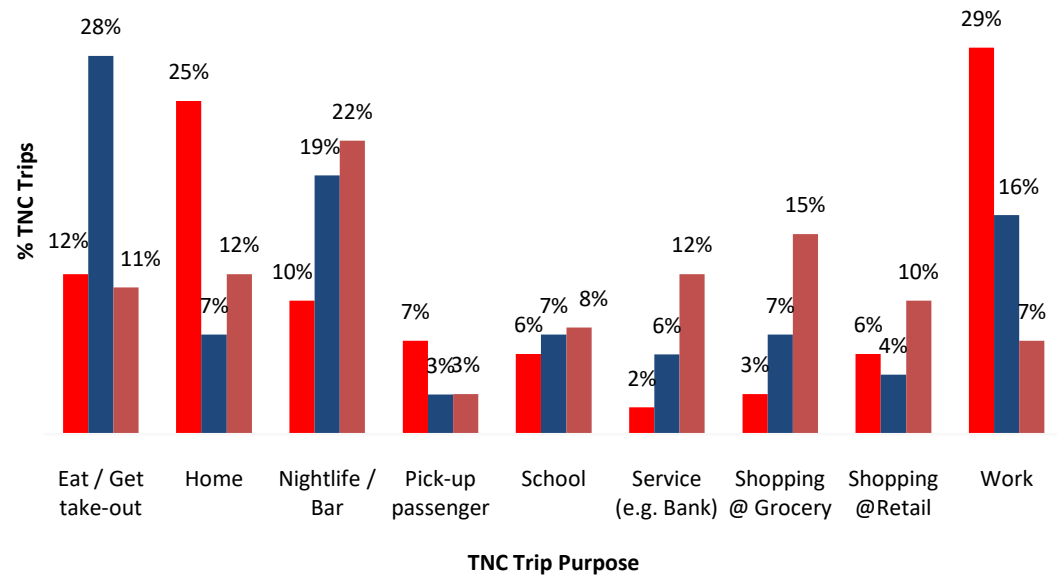

Figure 5. Trip purposes vs TNC trips.

The majority of Birmingham respondents use TNCs to travel to work (29\%) or home (25\%). During weekdays, the TNC trips to work in Miami Beach are just $16 \%$, noticeably lower to those in the Birmingham Metro area. This is expected, as the majority of the survey respondents in the Miami Beach area are either tourists or commute to Miami downtown with personal automobile. It can also be seen that the peak destinations for weekday TNC trips in the Miami Beach are restaurants (28\%) and nightlife/bar (19\%). As expected, during weekends in Miami Beach, the majority of the TNC trips are geared toward entertainment and shopping with trips to nightlife/bar (22\%) being the dominating trip purpose category.

The relationships between vehicle ownership, TNC usage, and TNC trip pur- 
pose are illustrated in Figure 6 (Birmingham) and Figure 7 (Miami Beach), respectively. In the Birmingham metro area, it is evident that individuals having vehicle ownership tend not to use TNC as a mode of transportation. Survey respondents having regular access to personal automobiles use TNC service occasionally to commute to work (17\%) or home (10\%) and for recreational purposes. In the Miami Beach area, the scenario is opposite to that of Birmingham. Despite personal vehicle ownership, survey respondents opted to use TNC service, primarily to access restaurants $(21 \%)$ and bars (13\%) during nighttime. When non-resident trips were excluded from the analysis, similar results were obtained with the majority of TNC trips by Miami Beach residents being destined to restaurants (40\%) and bars (13\%).

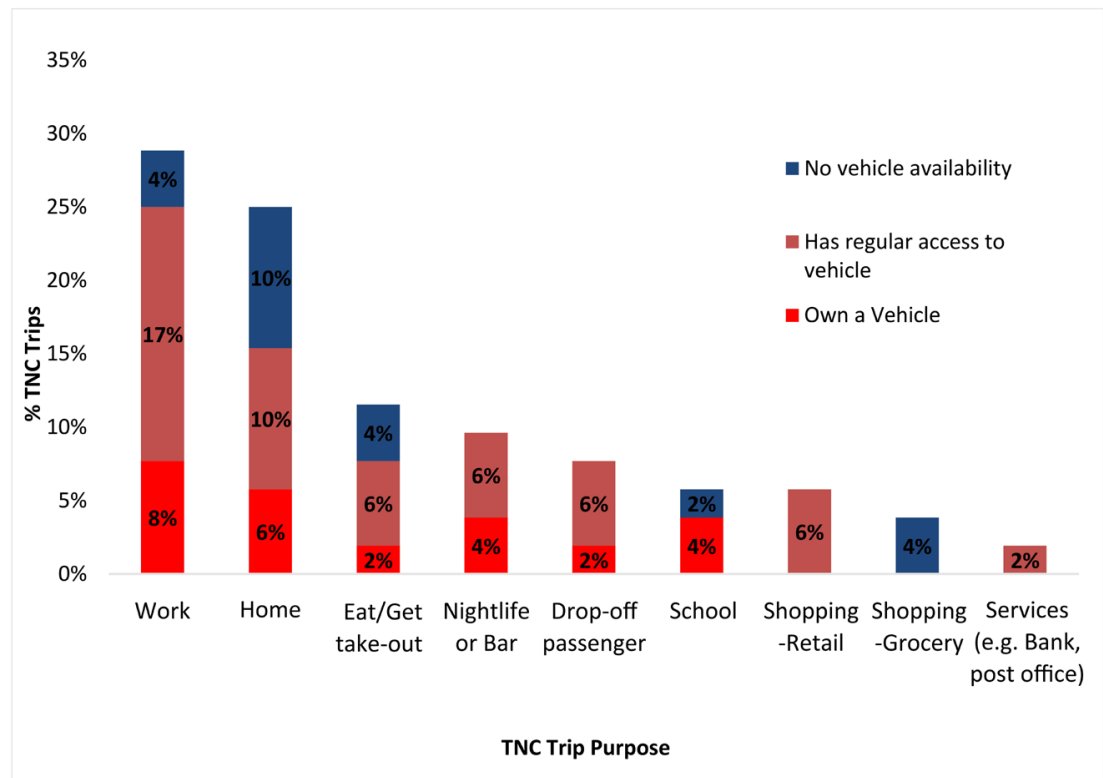

Figure 6. Car availability of TNC users (Birmingham). Source: [12].

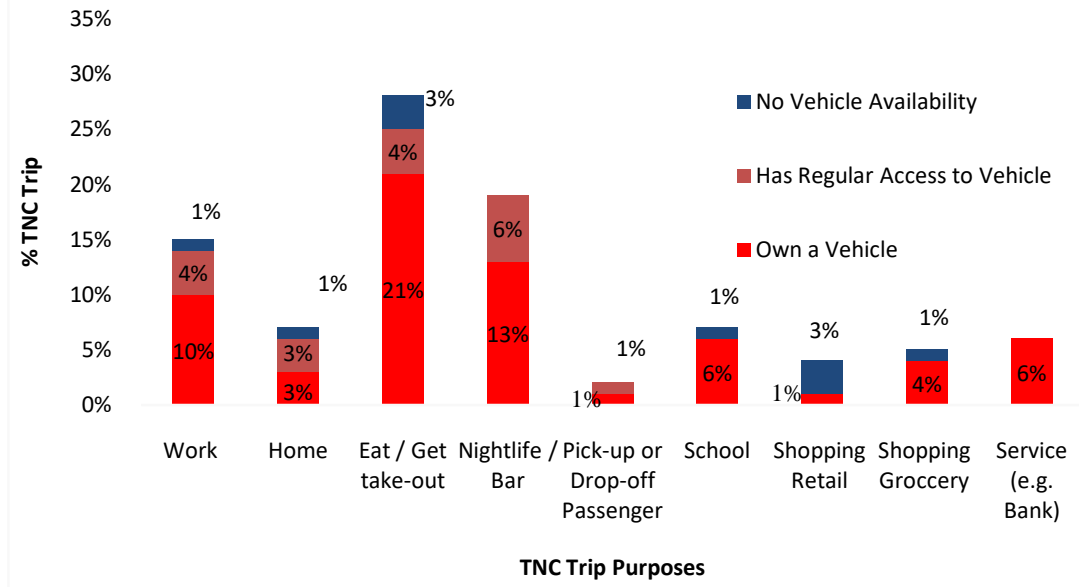

Figure 7. Car availability of TNC users (Miami Beach). 
Table 2 and Table 3 show the correlation between TNC trip time, waiting time and vehicle availability on mobile apps for the Birmingham and Miami Beach regions, respectively. TNC trip times are categorized based on the time of the day (i.e., daytime and nighttime). It can be observed that the range of waiting times is different for the two regions under consideration reflecting local conditions. The maximum waiting time for the Miami Beach region is more than 30 minutes (especially during weekends), whereas in Birmingham it is much shorter, ranging between 11 and 15 minutes. Also, the range of available vehicles in the app is different in both regions. In contrast to the maximum range of vehicles in Birmingham (3 - 5), the range of maximum vehicles in Miami Beach is more than 5 . The trips are equally allocated during day and night in both regions. The majority of the waiting times in Birmingham are between 0 - $5 \mathrm{mi}$ nutes, both in daytime (25\%) and nighttime (33\%). However, in Miami Beach, the majority of survey responders report waiting times that range between 5 - 15 minutes both during daytime (27\%) and nighttime (25\%), possibly reflecting the nature of the transportation network in Miami Beach that provide accessibility challenges to the drivers.

Table 2. Correlation of TNC trip time with waiting time and vehicle availability on app (Birmingham).

\begin{tabular}{cccc}
\hline Available vehicles on App & $\mathbf{1 - 2}$ & $\mathbf{3}-\mathbf{5}$ & Total \\
\hline Day-time trips & $\mathbf{3 8 \%}$ & $\mathbf{1 2 \%}$ & $\mathbf{5 0 \%}$ \\
0 - 5 minute & $19 \%$ & $6 \%$ & $25 \%$ \\
$11-15$ minutes & $4 \%$ & $4 \%$ & $8 \%$ \\
6 - 10 minutes & $15 \%$ & $2 \%$ & $17 \%$ \\
Night-time trips & $\mathbf{5 0 \%}$ & $\mathbf{0 \%}$ & $\mathbf{5 0 \%}$ \\
0 - 5 minute & $33 \%$ & $0 \%$ & $33 \%$ \\
$6-10$ minutes & $17 \%$ & $0 \%$ & $17 \%$ \\
Total & $\mathbf{8 8 \%}$ & $\mathbf{1 2 \%}$ & $\mathbf{1 0 0 \%}$ \\
\hline
\end{tabular}

Table 3. Correlation of TNC trip time with waiting time and vehicle availability on app (Miami Beach).

\begin{tabular}{ccccc}
\hline Available vehicles on App & None & $\mathbf{1 - 5}$ & $\mathbf{5 +}$ & Total \\
\hline Day-time trips & $\mathbf{4} \%$ & $\mathbf{3 1 \%}$ & $\mathbf{1 6 \%}$ & $\mathbf{5 1 \%}$ \\
$<5$ minute & $0 \%$ & $7 \%$ & $2 \%$ & $9 \%$ \\
$5-15$ minutes & $0 \%$ & $15 \%$ & $13 \%$ & $28 \%$ \\
$15-30$ minutes & $4 \%$ & $9 \%$ & $2 \%$ & $15 \%$ \\
More than 30 minutes & $0 \%$ & $0 \%$ & $0 \%$ & $0 \%$ \\
Night-time trips & $\mathbf{7 \%}$ & $\mathbf{3 3 \%}$ & $\mathbf{9 \%}$ & $\mathbf{4 9 \%}$ \\
$<5$ minute & $2 \%$ & $7 \%$ & $4 \%$ & $13 \%$ \\
$5-15$ minutes & $4 \%$ & $18 \%$ & $4 \%$ & $25 \%$ \\
$15-30$ minutes & $2 \%$ & $4 \%$ & $0 \%$ & $5 \%$ \\
More than 30 minute & $0 \%$ & $4 \%$ & $2 \%$ & $5 \%$ \\
Total & $11 \%$ & $64 \%$ & $\mathbf{2 5 \%}$ & $\mathbf{1 0 0 \%}$ \\
\hline
\end{tabular}


The survey participants in both study locations were asked about their preference with respect to future improvements related to transportations infrastructure and services. Figure 8 illustrates such preferences based on survey responses in the Birmingham and Miami Beach regions. Based on their responses, $26 \%$ and $19 \%$ of survey participants recommended an expansion of TNC services in the Birmingham and Miami Beach regions respectively. Furthermore, survey participants from both regions equally prioritized improving public transit facilities (43\%).

Survey respondents in Birmingham were also asked to note the reason(s) for using TNCs in the past. To identify the most influential reasons for selecting TNC services as a mode of transportation, the reasons stated by the respondents were factorized in terms of binary values where 1 is assigned to "selected values" and 0 is assigned to values that were "not selected". Table 4 documents the mean and standard deviation according to the survey responses.

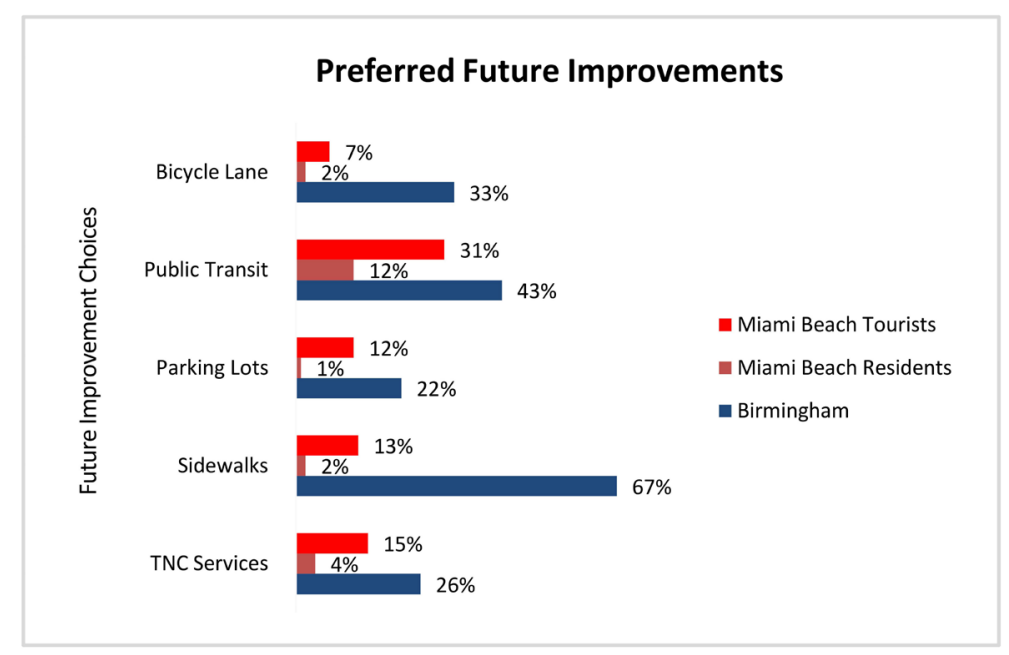

Figure 8. Preference for future improvements of transportation infrastructure and services.

Table 4. Summary characteristics of study sites and survey responses.

\begin{tabular}{ccc}
\hline Reason & Mean & Standard Deviation \\
\hline Convenience & 0.56 & 0.50 \\
Safety & 0.30 & 0.46 \\
No car availability & 0.27 & 0.44 \\
Destination has limited/no parking & 0.24 & 0.43 \\
Cheaper than alternatives & 0.21 & 0.41 \\
Parking at destination is expensive & 0.19 & 0.39 \\
Transit is not accessible & 0.06 & 0.23 \\
Transit is not reliable & 0.03 & 0.17 \\
Other reason & 0.03 & 0.18 \\
Other mode not available & 0.02 & 0.15 \\
\hline
\end{tabular}


The results clearly show that convenience was reported by transportation users in the Birmingham area as the main driving force for selection of TNCs as a travel mode. Safety/avoiding driving when intoxicated, and lack of automobile availability were cited as the second and third most important reasons for use of TNCs in the survey of Birmingham users.

The survey conducted in Birmingham also asked respondents with no previous TNC experience within the past year to mark the main reason for not considering TNCs as a mode of transportation. From Figure 9, it can observed that nearly $30 \%$ survey respondents reported that the use of TNCs was not convenient for them, while another $20 \%$ noted that they do not use TNCs due to associated cost. The "other reasons" that were cited by the survey respondents include personal preference to use other transportation modes, distance to destination making TNC unattractive, concerns about riding in another person's car and the lack of accommodations for individuals with limited mobility.

The study also confirmed that trip distance plays a role as a potential determinant of TNC use. According to the characteristics of the TNC trips reported in the Birmingham case study, TNC users use TNC services for trips under 10 miles. A comparison between TNC and non-TNC trips revealed that the average trip length performed by TNC was 5.19 miles, far lower than the average trip length of automobile trips (9.28 miles) in the region. Further analysis indicated that the longest TNC trips involved drop-off of a passenger or trips to work or home. The average trip length per trip purpose for TNC trips is shown in Figure 10.

The survey conducted in Miami Beach also requested feedback from respondents about their willingness to use ride-hailing services to commute if incentives or special services were provided. The four questions that were designed to portray the hypothetical scenarios are as follows:

- Willingness to use ride-hailing services for the first or last mile if incentives (discounts) are provided

- Willingness to use the ride-hailing services for commuting if the public transit service is made free

- Willingness to use the ride-hailing services for the first or last mile to reach home or to the nearby public transit stop or station, and

- Willingness to use the ride-hailing services for commuting if a rewards point system is introduced by their work place.

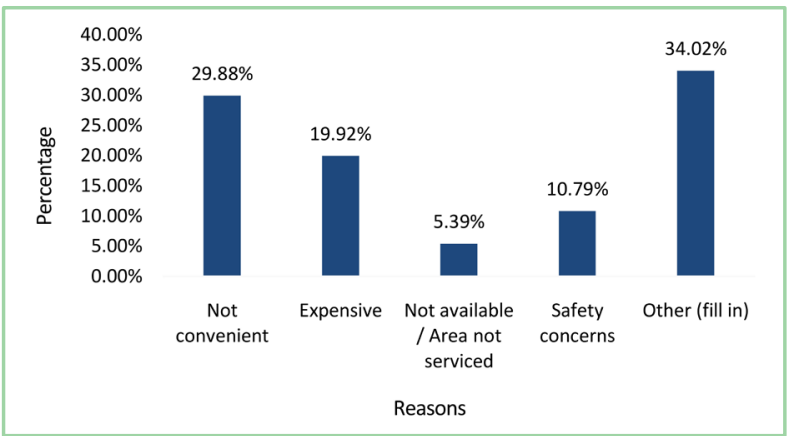

Figure 9. Reasons for not Using TNCs (Birmingham). 


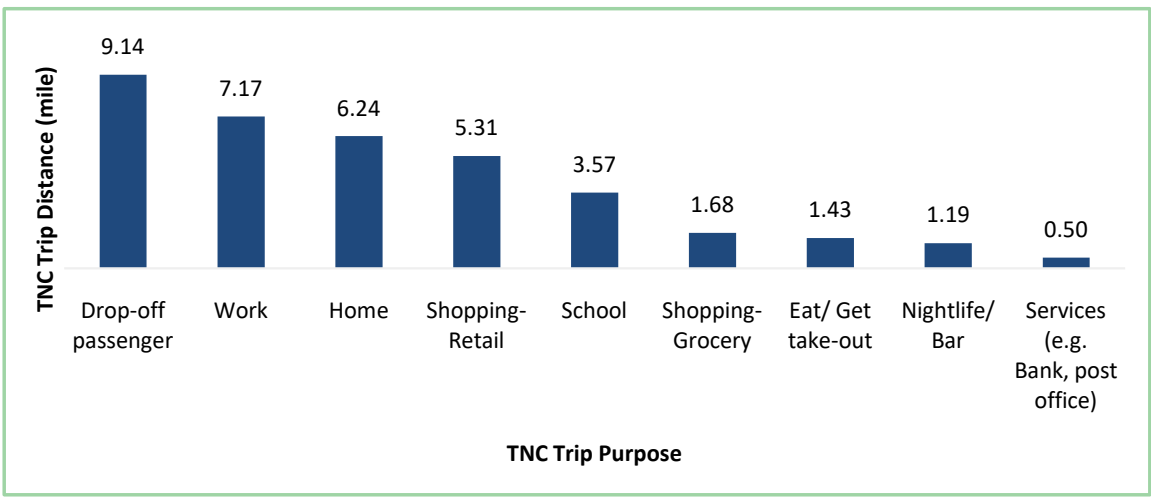

Figure 10. TNC trip distance (miles) for various trip purposes (Birmingham). Source: [12].

The majority of the respondents expressed their willingness to use the TNC services when incentives or special offers are provided as shown in Figure 11. The type of incentive offered appeared to make little difference in their response. Only $20 \%$ of the survey participants reported a complete lack of interest in considering TNC services for commuting purposes, even if incentives were offered. This is consistent with other studies that suggest that automobile-dependent users show resistance in embracing alternative modes [16].

\subsection{Regression Analysis}

In addition to the descriptive analysis, the study employed the Least Absolute Shrinkage and Selection Operator (Lasso), a very popular machine learning algorithm [17], to perform regression analysis. The purpose of this effort was to identify parameters that can be used to predict TNC use. Lasso regression provides two major advantages over linear regression, which made it an attractive alternative to linear regression, namely 1 ) clear variable or feature selection and 2) better prediction accuracy. Lasso regression, through shrinkage or regularization of the coefficients, increases the prediction accuracy and decreases the variance of the model interpretability. This regression technique selects strong variables in high dimension data for clearer interpretations of the results since models with too many variables are hard to interpret [18]. Additionally, Lasso regression eliminates over-fitting, i.e., large variance and unbiased estimates, which increases prediction accuracy [19].

In Lasso regression, categorical variables are encoded into a set of indicators by transforming the variables into factors. Consequently, a dummy variable matrix of predictors is created, along with continuous predictors to serve as inputs to the model. Dummy coding includes binary attributes to indicate category membership. The reference category is indicated as " 0 " and corresponding category is coded as " 1 " in the dummy coding. As shown in Equation (1), Lasso adds a penalty term i.e., product of a bias parameter $\lambda$ with the absolute value of the slope to regulate the size of the coefficients $\left(\beta_{\text {lasso }}\right)$ which can affect the number of predictors included in the model. 


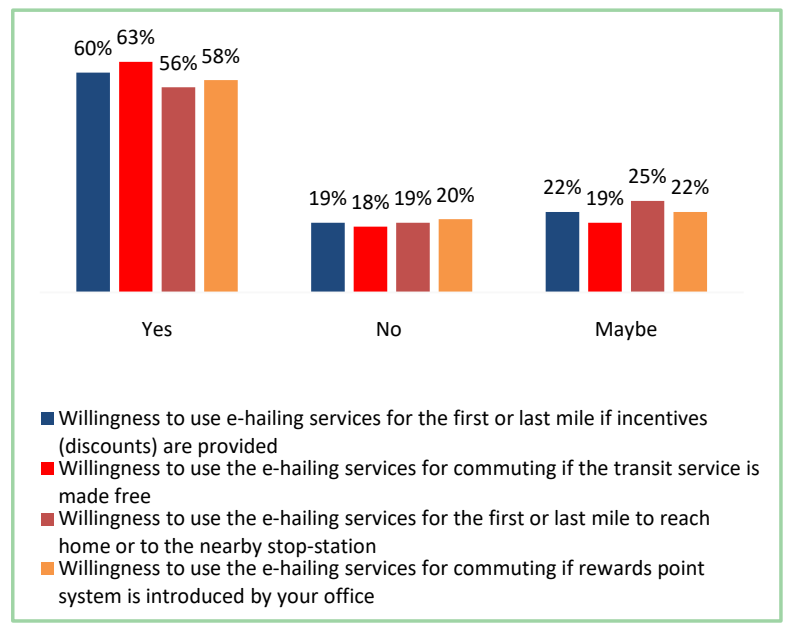

Figure 11. Willingness to use ride-hailing services in hypothetical scenarios (Miami Beach).

$$
\beta_{\text {lasso }}=\operatorname{Min}(\text { Sum of squared residuals })+\lambda * \mid \text { slope } \mid
$$

The tuning parameter $(\lambda)$ is chosen by cross validation, i.e. when $\lambda=0$ mean square error is 0 . As $\lambda$ increases, shrinkage occurs so that the variables that are insignificant ("0" value) are eliminated.

In this study, the Lasso method was applied separately on the Miami Beach Survey and Birmingham Survey Data. There were 155 baseline variables for the Miami Beach case study and 103 base line variables for the Birmingham case study. $80 \%$ of the data was used to train the model and the remaining $20 \%$ was used for model predictions. The dependent variable " $y$ " represented the TNC usage among the respondents in both study regions. The estimated coefficients and the variables selected under the Lasso method considered only features that were significant for the model fitting.

Lasso fits the most significantly contributed variables by making the insignificant variables exactly to zero. Figure 12 shows the shrinkage of the coefficients towards zero to eliminate the insignificant variables present in the two models developed in this study (i.e., Miami Beach and Birmingham models).

Figure 13 represents selection of the optimum value of $\lambda$ using cross validation. The optimum $\lambda$ value for Miami Beach and Birmingham model were 0.009294 and 0.00088 respectively. The graphs indicate that the unregularized models are a good fit. The best mean squared error (MSE) were $13.75 \%$ and $0 \%$ for the Miami Beach and Birmingham models, respectively.

The application of the Lasso procedure resulted in the elimination of $123 \mathrm{va}$ riables and 101 variables from Miami Beach and Birmingham survey respectively. Finally, the method led to the selection of 32 variables for the Miami Beach model and 2 variables for the Birmingham model.

Figure 14 showcases the results from the regression analysis by fitting the model with significant independent variables identified by the Lasso method. For the Miami Beach model, notable features such as car availability, vehicle ownership, availability of Uber/Lyft, age range (18 - 29), high income (>\$75 K), 
Miami residency etc., possess positive significance for using TNC services in the Miami Beach region. Additionally, features such as lack of prior use of public transit, lack of use of TNC services and interest in future expansion of sidewalks possess a negative significance with respect to using TNC services in the Miami Beach area. In the Birmingham region only two parameters, namely car availability and waiting time were found to be significant predictors to choosing TNC as a mode of transportation.

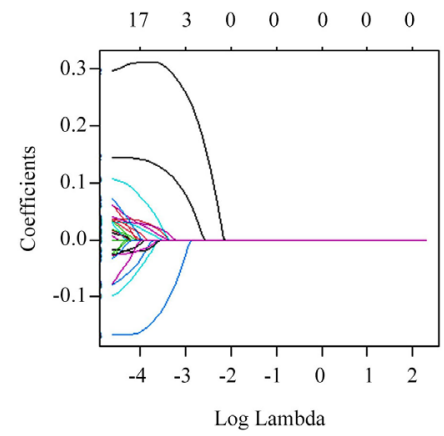

(a)

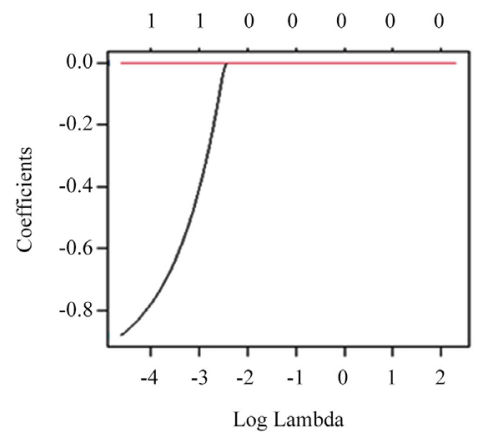

(b)

Figure 12. Coefficient Shrinkage for (a) Miami Beach Model; and (b) Birmingham Model.

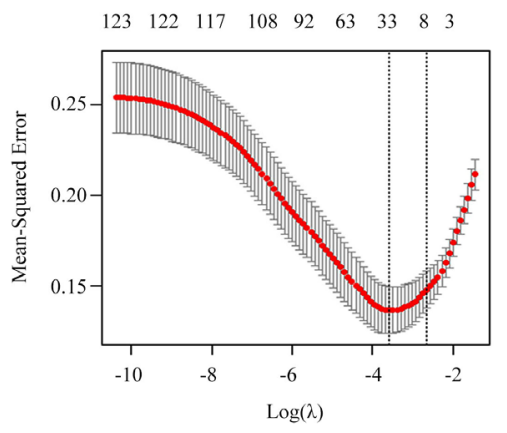

(a)

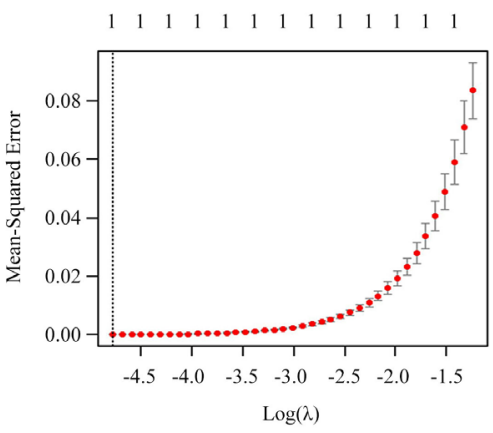

(b)

Figure 13. Optimum Tuning Parameter for (a) Miami Beach Model; and (b) Birmingham Model.
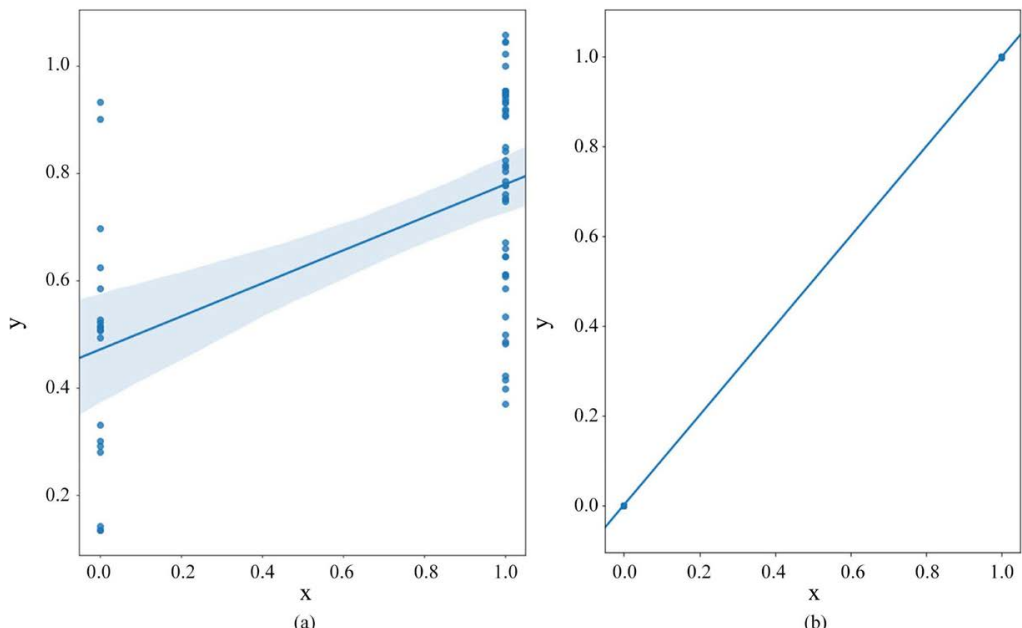

Figure 14. Regression Model-Fit for (a) Miami Beach Model; and (b) Birmingham Model. 


\section{Conclusions}

The analysis of 790 questionnaire surveys of transportation system users in the Birmingham and Miami Beach region shed light on users' awareness and use of TNC services in the Southeastern US. Examination of the survey participants' responses confirmed that TNC service coverage and other geographic considerations and user characteristics impact user perceptions and adoption of such services. Thus, local transportation users' surveys are an important tool to document travelers' preferences and guide planning of TNC services accordingly.

The study also confirmed that, even in small- and medium-size urban areas, transportation users are aware of ride-hailing services and are taking advantage of them. It was also found that the trip purpose for using TNC services varied according to the composition of the survey participants (i.e., local residents versus visitors/tourists). Residents used TNC trips more for trips to home or work while visitors chose ride-hailing trips mostly to access entertainment establishments including restaurants and bars.

An interesting difference between the findings from the two surveys was the relationship between vehicle ownership and TNC use. In the highly automobiledependent Birmingham market, TNC use was more closely linked to need (i.e., lack of vehicle availability) than choice, while the opposite was the case in the Miami Beach case study.

The findings of the surveys also helped us to define the profile of the typical TNC user in the study regions. In the Birmingham metro area the typical TNC users are 25 - 34 years of age that use the ride-hailing services for commuting or entertainment purposes for short to medium range distances (or average of 5 miles). The typical profile of a Miami Beach TNC user is that of younger traveler (18 - 29 years of age) that uses the ride-hailing service primarily for entertainment purposes, especially during weekends in order to get to the tourist-attraction locations.

Finally, the model fitting exercise identified predictors for TNC use. For the Birmingam region, TNC use was strongly correlated with vehicle availability and waiting time. Several independent variables were identified as significant predictors of TNC use in the Miami Beach model including vehicle availability, vehicle ownership, availability of Uber/Lyft, age range (18 - 29), high income (>\$75 $\mathrm{K})$, and residency.

Overall, the study findings establish valuable links between travel behaviors and TNC use. These can inform transportation agencies about the needs and opportunities for ride-hailing services in the local market. The findings can also be used to create targeted marketing plans and incentives to encourage mode switching to shared modes, including TNCs. Overall, the study highlights the importance of understanding the user characteristics of the local market when planning for TNC and other ride-sharing services in the future.

\section{Acknowledgements}

The study was conducted under the US DOT-STRIDE sponsored project "Miti- 
gating Network Congestion by Integrating Transportation Network Companies and Urban Transit".

\section{Conflicts of Interest}

The authors declare no conflicts of interest regarding the publication of this paper.

\section{References}

[1] Hartmans, A. and Leskin, P. (2018) The History of How Uber Went from the Most Feared Startup in the World to Its Massive IPO. Business Insider.

https://www.businessinsider.com/ubers-history

[2] National Research Council Committee for Review of Innovative Urban Mobility Services (2015) Between Public and Private Mobility Examining the Rise of Technology-Enabled Transportation Services. Transportation Research Board, Washington DC.

[3] Sisiopiku, V.P., Hadi, M., McDonald, N., Steiner, R. and Ramadan, O.E. (2019) Technology Influence on Travel Demand and Behaviors. Final Report to the Southeastern Transportation Research, Innovation, Development and Education Center (STRIDE)

[4] Shaheen, S. (2018) Shared Mobility: The Potential of Ride Hailing and Pooling. In: Sperling, D., Ed., Three Revolutions: Steering Automated, Shared, and Electric Vehicles to a Better Future, 2nd Edition, Island Press, Washington DC, 55-76.

https://escholarship.org/uc/item/46p6n2sk

https://doi.org/10.5822/978-1-61091-906-7_3

[5] Clewlow, R.R. and Mishra, G.S. (2017) Disruptive Transportation: The Adoption, Utilization, and Impacts of Ride-Hailing in the United States. Institute of Transportation Studies, University of California, Davis.

[6] Vinayak, P.F., Dias, F.F., Astroza, S.F., Pendyala, R.F. and Garikapati, V.M. (2018) Accounting for Multidimensional Dependents among Decision-Makers within a Generalized Model Framework: An Application to Understanding Shared Mobility Service Usage Levels. Transport Policy, 77, 129-137.

https://doi.org/10.1016/j.tranpol.2018.09.013

[7] Chen, Z. (2015) Impact of Ride-Sourcing Services on Travel Habits and Transportation Planning. http://d-scholarship.pitt.edu/25827

[8] Circella, G., Alemi, F., Berliner, R., Tiedeman, K., Lee, Y., Fulton, L., Handy, S. and Mokhtarian, P.L. (2017) The Multimodal Behavior of Millennials: Exploring Differences in Travel Choices between Young Adults and Gen Xers in California. Research Report UCD_ITS_RR_17-54, University of California, Institute of Transportation Studies, Davis.

https://itspubs.ucdavis.edu/wp-content/themes/ucdavis/pubs/download pdf.php?id $=2872$

[9] Freund, K., Bayne, A., Beck, L., Siegfried, A., Warren, J., Nadel, T. and Natarajan, A. (2020) Characteristics of Ride Share Services for Older Adults in the United States. Journal of Safety Research, 72, 9-19. https://doi.org/10.1016/j.jsr.2019.12.008

[10] Rayle, L., Shaheen, S., Chan, N., Dai, D. and Cervero, R. (2014) App-Based, OnDemand Ride Services: Comparing Taxi and Ridesourcing Trips and User Characteristics in San Francisco. University of California Transportation Center (UCTC) Technical Report, UCTC-FR-2014-08. 
[11] Smith, A. (2016) On-Demand: Ride-Hailing Apps. In: Shared, Collaborative and on Demand, Pew Research Center: Internet, Science and Tech, Chapter 2. https://www.pewresearch.org/internet/2016/05/19/the-new-digital-economy/

[12] Sarjana, S., Ramadan, O.E. and Sisiopiku, V.P. (2020) Analysis of Transportation Users' Preferences and Attitudes for Identifying Micro-Level Determinants of Transportation Network Companies' (TNCs) Growth. Journal of Transportation Technologies, 10, 251-264. https://www.scirp.org/pdf/jtts 2020061810033242.pdf https://doi.org/10.4236/jtts.2020.103016

[13] Institute of Transportation Engineers (ITE) (2011) Manual of Transportation Engineering Studies. 2nd Edition, Vol. 12.

[14] Sisiopiku, V. (2018) Travel Patterns and Preferences of Urban University Students. Athens Journal of Technology and Engineering, 5, 19-31.

https://doi.org/10.30958/ajte.5-1-2

[15] Sisiopiku, V.P. and Ramadan, O.M. (2018) Understanding Women's Needs as Determinants of Mode Choice: A Case Study of the University of Alabama at Birmingham. Annual Meeting Online Proceedings of the TRB 97 th Annual Meeting, Washington DC, 8 January 2018, 10 p. https://trid.trb.org/view/1495499

[16] Morshed, S.A., Arafat, M., Ashraf Ahmed, M. and Saha, R. (2020) Discovering the Commuters' Assessments on Disaster Resilience of Transportation Infrastructure. In: International Conference on Transportation and Development 2020, American Society of Civil Engineers, Reston, 23-34. https://doi.org/10.1061/9780784483169.003

[17] Tibshirani, R. (1996) Regression Shrinkage and Selection via the Lasso. Journal of the Royal Statistical Society, 58, 267-288. https://doi.org/10.1111/j.2517-6161.1996.tb02080.x

[18] Hastie, T., Robert, T. and Wainwright, M. (2015) Statistical Learning with Sparsity: The Lasso and Generalizations. Chapman and Hall/CRC, New York. https://doi.org/10.1201/b18401

[19] Steele, A.J., Denaxas, S.C., Shah, A.D., Hemingway, H. and Luscombe, N.M. (2018) Machine Learning Models in Electronic Health Records can Outperform Conventional Survival Models for Predicting Patient Mortality in Coronary Artery Disease. PLoS ONE, 13, e0202344. https://doi.org/10.1101/256008 